\title{
Rogue waves on the general periodic travelling waves background for an extended modified Korteweg-de Vries equation
}

\author{
Yi Zhang ${ }^{1}, \mathrm{Yu} \mathrm{Lou}^{1}$, and RS Ye ${ }^{1}$ \\ ${ }^{1}$ Zhejiang Normal University
}

February 28, 2021

\begin{abstract}
Under consideration in this paper is rogue waves on the general periodic travelling waves background of an integrable extended modified Korteweg-de Vries equation. The general periodic travelling wave solutions are presented in terms of the sub-equation method. By means of the Darboux transformation and the nonlinearization of the Lax pair, we present the first-, second- and third-order rogue waves on the general periodic travelling waves background. Furthermore, the dynamic behaviors of rogue periodic waves are elucidated from the viewpoint of three-dimensional structures.
\end{abstract}

\section{Hosted file}

emKdV(2).pdf available at https://authorea.com/users/398622/articles/511267-rogue-waves-onthe-general-periodic-travelling-waves-background-for-an-extended-modified-korteweg-devries-equation

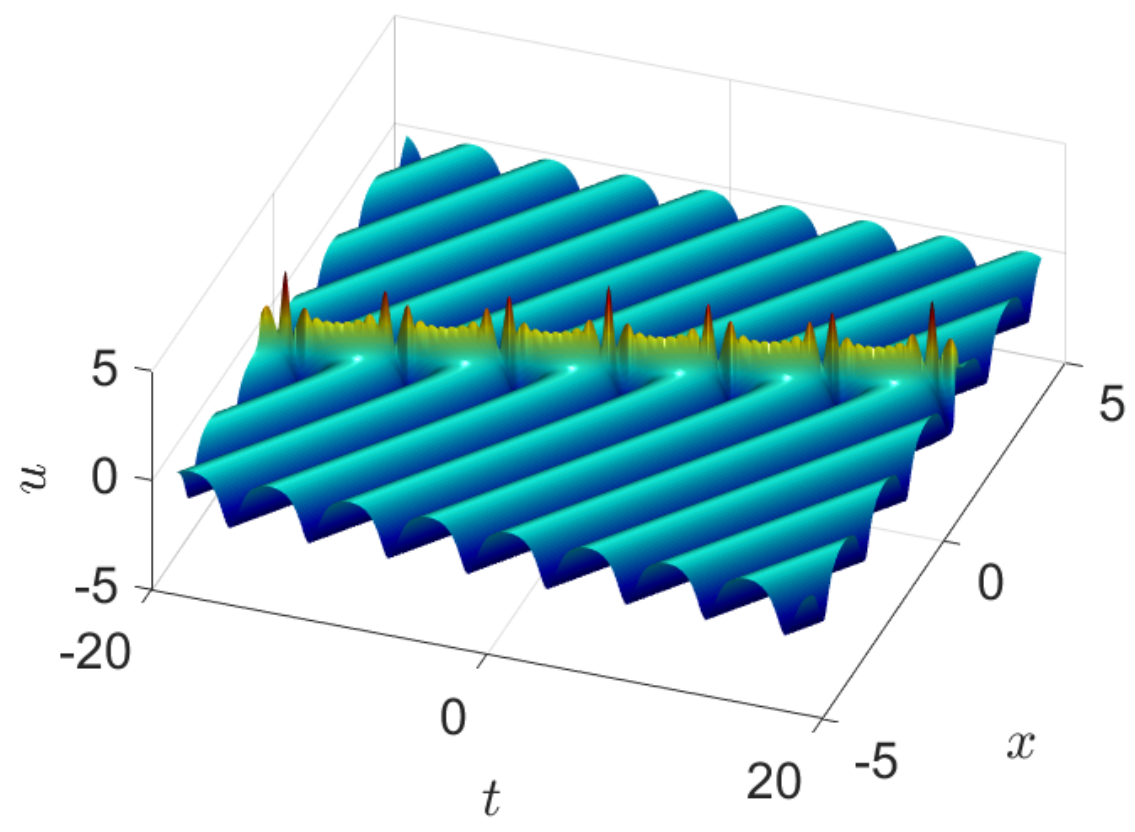



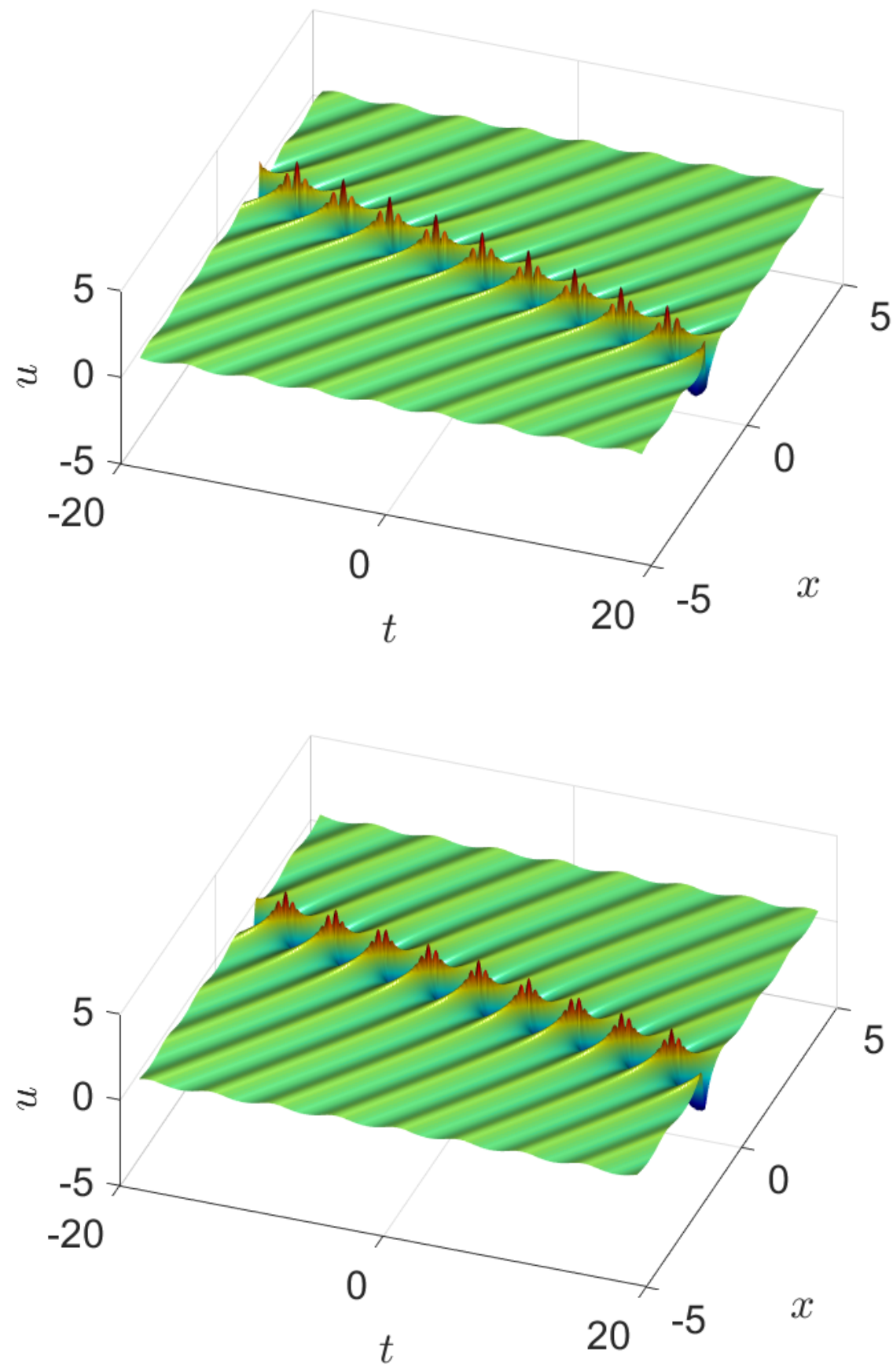

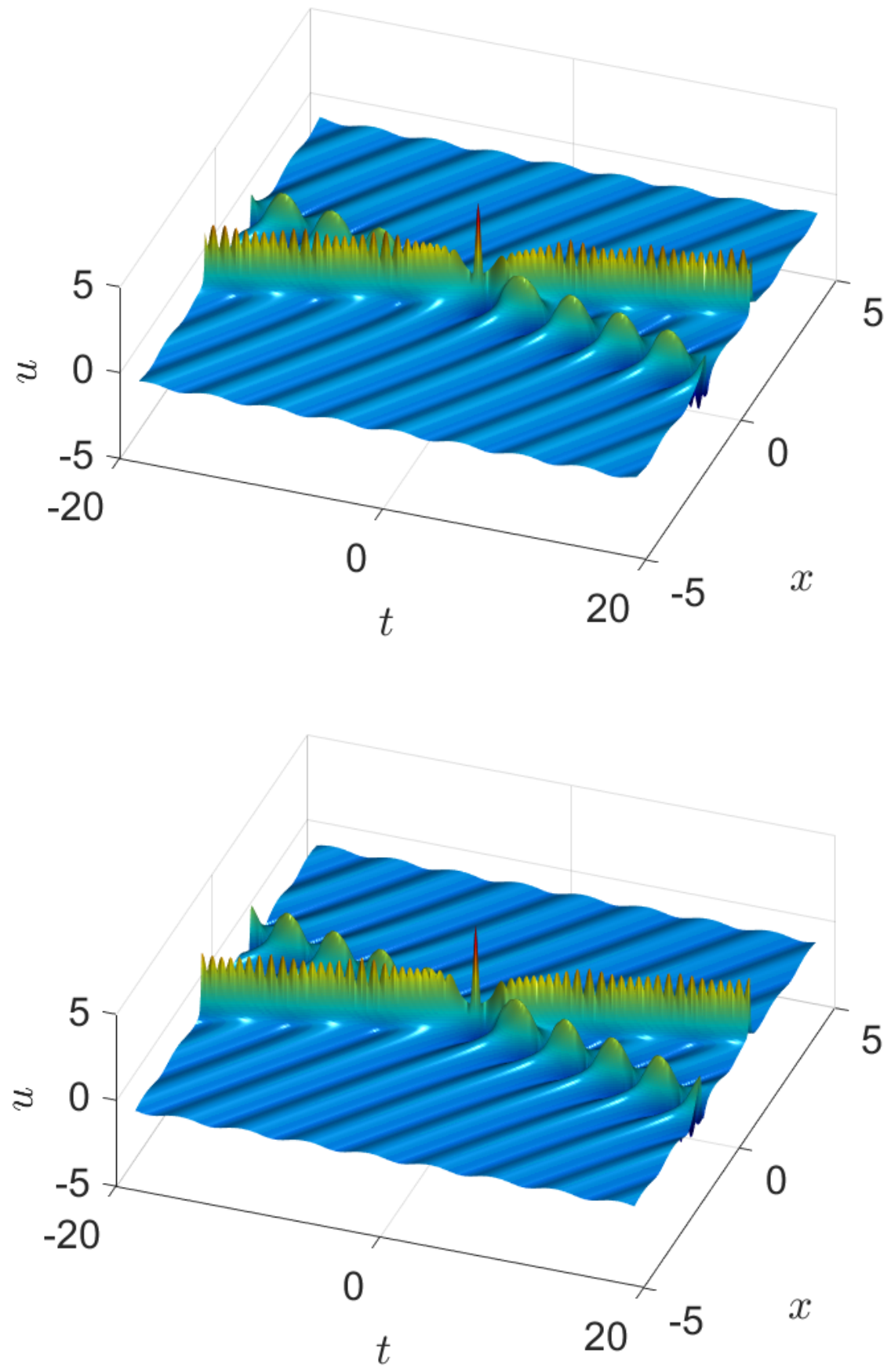

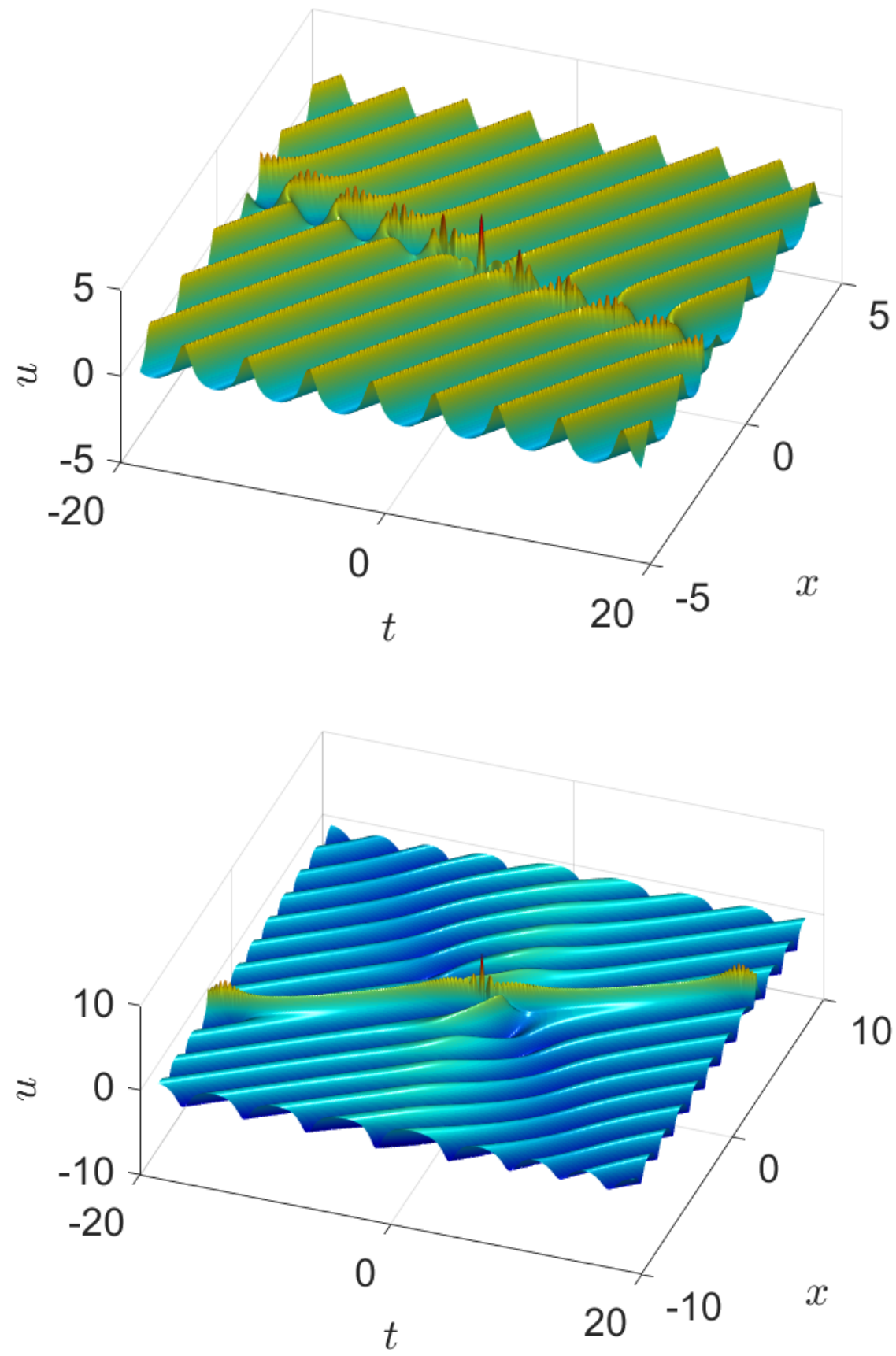

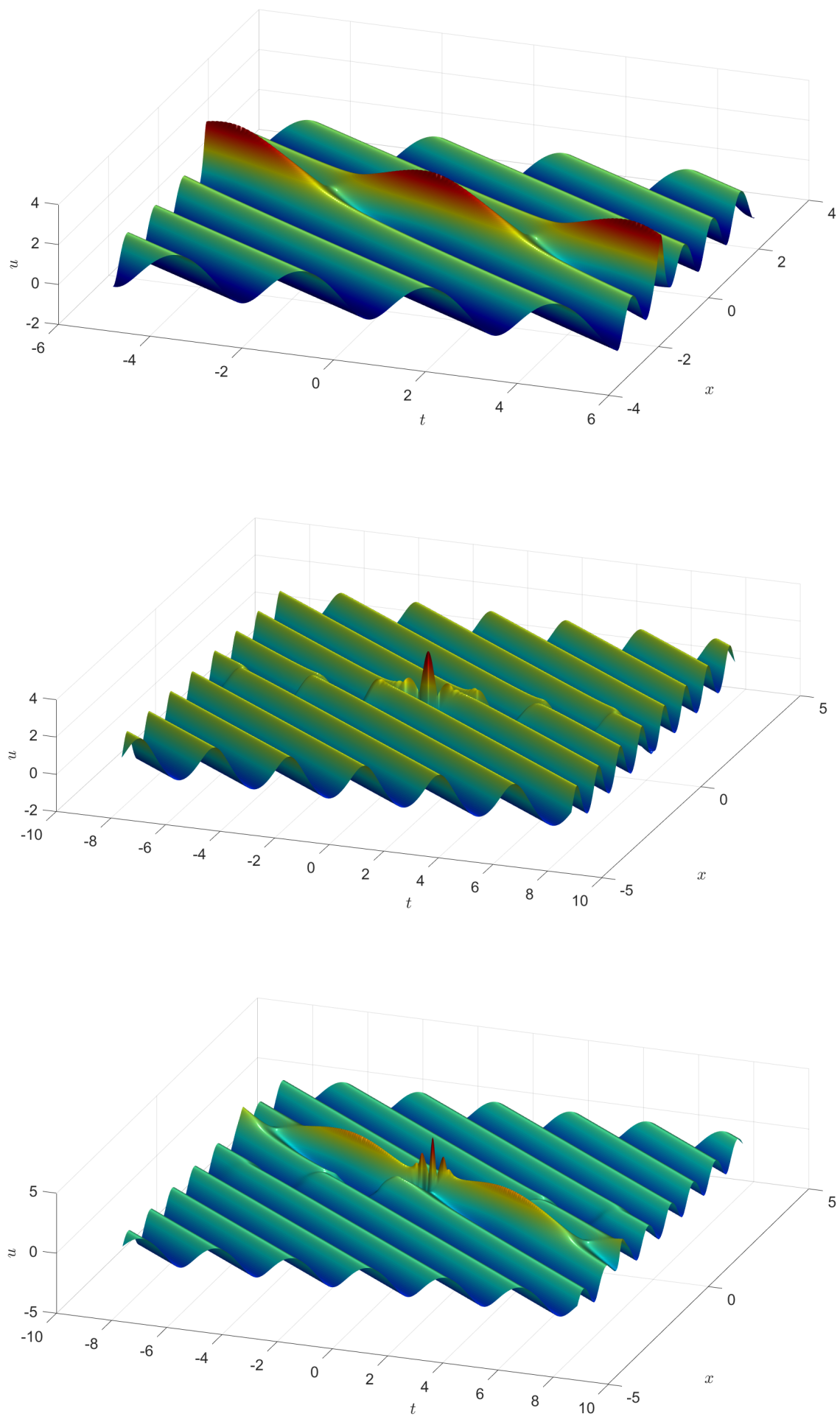